\title{
Recent progress in the management of chronic cough
}

\author{
Woo-Jung Song ${ }^{1}$, Jin $\mathrm{An}^{1}$, and Lorcan McGarvey ${ }^{2}$
}

\begin{abstract}
${ }^{1}$ Department of Allergy and Clinical Immunology, Airway Sensation and Cough Research Laboratory, Asan Medical Center, University of Ulsan College of Medicine, Seoul, Korea; ${ }^{2}$ Wellcome-Wolfson Institute for Experimental Medicine, School of Medicine, Dentistry and Biomedical Sciences, Queen's University Belfast, Belfast, UK
\end{abstract}

Received: January 13, 2020

Accepted: March 9, 2020

\section{Correspondence to} Lorcan McGarvey, M.D.

Wellcome-Wolfson Institute for Experimental Medicine, School of Medicine, Dentistry and Biomedical Sciences, Queen's University Belfast, 97 Lisburn Rd, Belfast BT9 7BL, UK

Tel: +44-2890976377

E-mail:1.mcgarvey@qub.ac.uk https://orcid.org/0000-00022860-0302
Chronic cough is a common clinical condition with significant impact on quality of life and for which effective therapy remains an unmet clinical need. Over the past decade, there has been a major shift in how we approach this problem, driven by better appreciation of the clinical manifestation of chronic cough and an improved understanding of the associated neurobiology. "Cough hypersensitivity syndrome" has been proposed as a new diagnostic term for chronic cough, encompassing different phenotypes of the condition. Accumulating evidence suggests that this new concept is clinically relevant. However, while it is gaining widespread endorsement within the allergy and respiratory community, raising its profile in routine clinical practice is a priority. Thus, the present paper reviews recent progress in our understanding and management of chronic cough, with focus on mechanistic and clinical studies. It also provides detail on knowledge gaps and future research directions.

Keywords: Cough; Hypersensitivity; Review

\section{INTRODUCTION}

The cough reflex is a vital physiological mechanism to clear unwanted material from the lungs and prevent aspiration [1]. Cough is regulated by coordinated interaction between the airway sensory nerves, brainstem and higher brain regions, enabling effective removal of irritants from the lower airways [2]. However, following a respiratory viral infection, the cough reflex may become sensitized, leading to irresistible bouts of coughing triggered by exposure to relatively innocuous stimuli [3]. In most cases, post-viral cough settles after a few weeks although it may take longer to resolve $[4,5]$.
Chronic cough, defined as a cough persisting for more than 8 weeks, is a clinical condition which can be difficult to treat and has received widespread clinical attention in recent years [6-10]. It is common in the community, affecting approximately $10 \%$ of the general adult populations worldwide, and approximately $2 \%$ to $5 \%$ in Asia Pacific countries including Korea [11-13]. Its higher prevalence among the elderly suggests that the burden of chronic cough may potentially continue to increase [14]. Although not directly related to mortality, chronic cough impacts a range of daily activities causing significant impairment of quality of life (QoL), frequently leading to social isolation of affected individuals [15-18]. 
The development of what was termed the "anatomic diagnostic protocol," which advocated systematic evaluation of potential causes based on the anatomical distribution of the vagal afferent sensory nerves regulating cough, was the first clinical breakthrough to improve the management of patients with chronic cough [19]. Earlier studies reported that almost all patients with chronic cough could be successfully managed using this systematic approach [19,20]. However, later clinical experience did not match the initial optimism, as $10 \%$ to $40 \%$ of patients visiting referral clinics remain unexplained or refractory to currently available treatments [21]. This unmet clinical need led to the revised outlook of the pathophysiological mechanisms underlying chronic cough [22,23]; and in 2014, a new paradigm of cough hypersensitivity syndrome (CHS) was proposed by the European Respiratory Society (ERS) Task Force [24]. CHS is defined as "a clinical syndrome characterized by troublesome coughing often triggered by low levels of thermal, mechanical, or chemical exposure" [24], reflecting symptom profiles described by many patients. Many patients with chronic cough report triggering of coughing by trivial environmental or behavioral factors such as exposure to cold or dry air, perfumes and aerosols, talking on the phone, or eating crumbly food (termed allotussia) [25-27]. The term 'CHS' also reflects what is now considered the principal underlying pathophysiological mechanism namely, cough reflex hypersensitivity [28]. Based on recent neurobiological studies, inflammation-induced injury causing functional changes of the neural pathways are suggested to lead to the sensitization of the cough reflex and perhaps its persistence [3].

The validity of this new concept is supported by a number of promising early phase clinical trials with antitussives targeting the neuronal pathways responsible for cough [29-32]. In addition, with help of sophisticated cough measurement tools, imaging techniques and mechanistic studies, we are gaining more understanding of the pathophysiology of chronic cough or CHS [3,33-35], although these advances are also giving rise to more new questions. In this review, we provide an overview of recent progress in this field, with a focus on major mechanistic studies and clinical trials. We also discuss current knowledge gaps and future application of concepts discussed to clinical practice.

\section{INSIGHTS FROM RECENT MECHANISTIC STUDIES}

Functional or phenotypic changes in peripheral sensory neurons may be the first-level adaptive host responses in terms of developing cough reflex hypersensitivity. A wide variety of external and internal triggers, such as viral infection, allergens, eosinophils, air pollutants or subsequent airway inflammation, may induce a functional hypersensitive status in the cough reflex, accompanied by functional or phenotypic changes in neurons (Fig. 1).

Clinically, respiratory viral infection is a common cause of cough [36] and may enhance capsaicin cough sensitivity [37]; and mechanistically, the viral infection or inflammatory sequelae may induce functional changes in sensory neurons [38]. In in vitro experiments using human rhinovirus and IMR-32 neuroblastoma cell lines differentiated into sensory neuron phenotypes, there is evidence that the virus infects the neuronal cells and rapidly upregulates the expression of transient receptor potential channel vanilloid-1 (TRPV1) and ankyrin-1 (TRPA1) implicated in cough induced by chemical and physical irritants [38]. In guinea pig experiments, parainfluenza-3 virus infection led to enhanced cough sensitivity to capsaicin, citric acid, and bradykinin, and upregulated gene expression of TRPV1 in the vagal ganglia [39].

Similar functional and phenotypic changes in airway sensory neurons were also observed in experimental models of allergic inflammation. In ovalbumin-sensitized guinea pigs, ovalbumin challenge induced de novo TRPV1 gene expression in tracheal nodose ganglionic neurons [40]. Eosinophils may directly induce cough hypersensitivity, probably through their cationic proteins; eosinophil major basic proteins directly enhanced chemical and mechanical sensitivity of pulmonary afferent C-fibres in rats and also induced cough sensitivity to irritants in mice [41]. In a study of human asthmatics, the number of airway and blood eosinophils correlated with the length of airway nerves and the number of nerve branch points [42]. In addition, in another study of allergic asthmatics, allergen inhalation challenge significantly increased capsaicin cough responses and also spontaneous coughs over 24 hours in allergic asthmatics, compared to diluent inhalation (negative control) [43]. Cigarette smoke extracts or particulate matter 2.5 


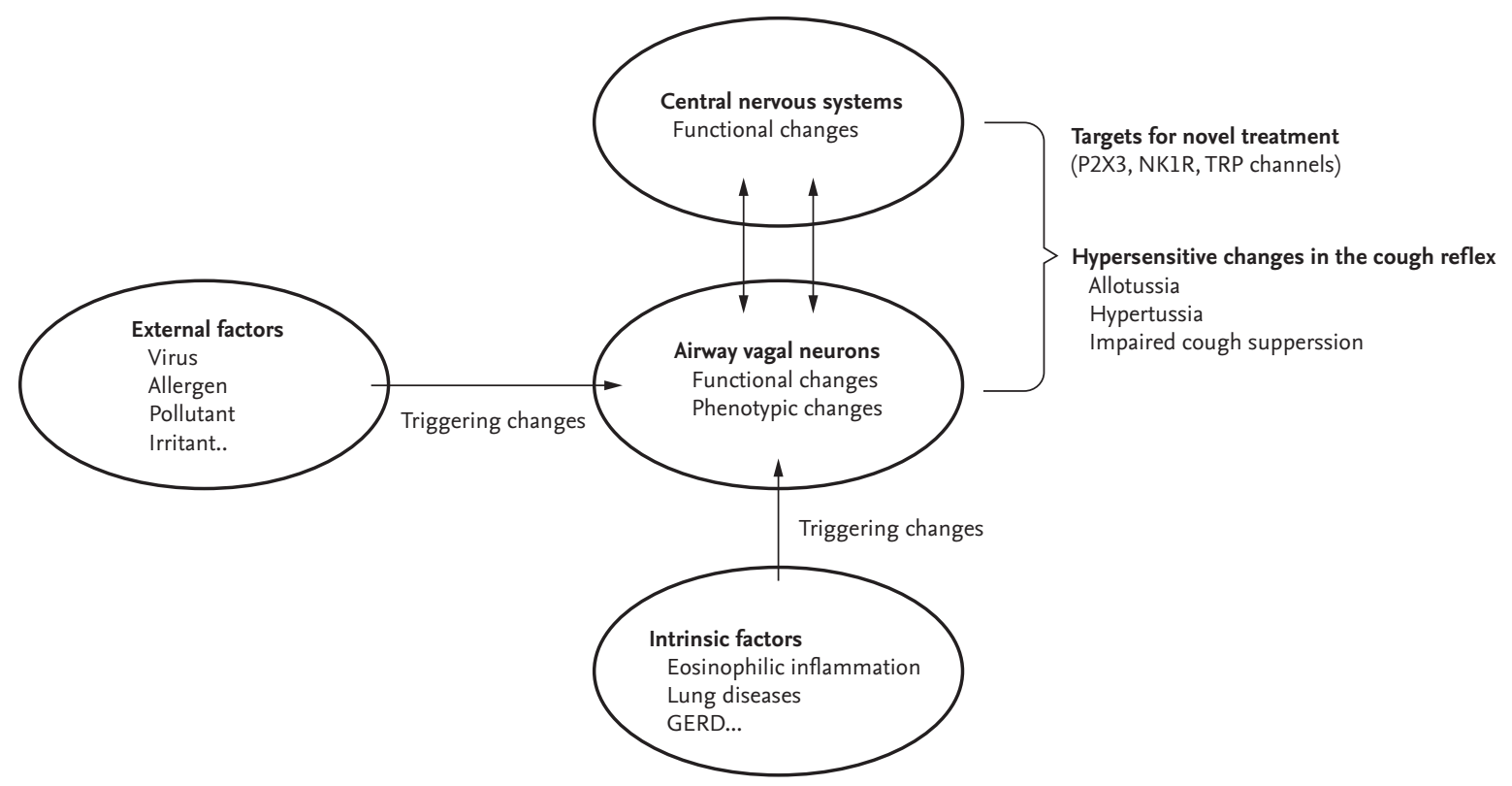

Figure 1. Schematic presentation of pathophysiologic components of cough hypersensitivity syndrome. Functional or phenotypic changes in peripheral sensory neurons are the first-level adaptive host responses in terms of developing cough reflex hypersensitivity, and may be accompanied by functional changes in the central neural processing of the cough reflex. These changes are now considered central to chronic cough. Primarily, the changes may be triggered by external factors such as viral infection, allergens, air pollutant or irritants, but also by intrinsic factors (disease conditions) such as eosinophilic inflammation, lung diseases, or gastroesophageal reflux disease. Patients with chronic cough commonly present with hypersensitivity, including allotussia, hypertussia, and impaired cough suppression, although the pattern of hypersensitivity may differ between individuals. It is unknown how airway vagal sensory neurons interact with central nervous systems in developing and maintaining chronic hypersensitive status of the cough reflex. Meanwhile, novel antitussives are being developed for patients with chronic refractory cough, targeting specific neuronal pathways implicated in the cough reflex, such as $\mathrm{P}_{2} \mathrm{X}_{3}$, neurokinin-1-receptor $(\mathrm{NK1R})$, or transient receptor potential channels. GERD, gastroesophageal reflux disease; TRP, transient receptor potential.

may also provoke similar changes in the airway nervous systems, although precise effects may differ between stimuli [44-46].

In humans, inhalation tussigen challenge tests are utilized to assess cough reflex sensitivity and may reveal enhanced cough responses (termed hypertussia) in patients with chronic cough. Commonly used agents include capsaicin, citric acid, distilled water, or adenosine triphosphate (ATP) and protocols for inhalation cough challenge testing and the use of the $\mathrm{C}_{2}$ or $\mathrm{C}_{5}$ endpoints (i.e., the concentration of tussigen causing two or five cough respectively) have been standardized [47]. Within individuals, capsaicin cough sensitivity increases during respiratory viral infection [37], and it also decreases by the resolution of coughing [48]. However, the tests are currently utilized for research purposes rather than for their clinical value due to their poor discriminatory ability between cough patients and healthy subjects contrasting the utility of bronchoprovocation challenge testing with agents such as methacholine or histamine [47]. In a recent study using ATP cough challenge tests, patients with chronic cough showed heightened cough response at lower concentration of ATP than healthy controls; however, the difference between groups was small [49].

The limited value of existing cough challenge testing has led to consideration of alternative challenge endpoints. In a nonlinear mixed-effects pharmacodynamic modeling study by Hilton et al. [50], recording the maximal cough response evoked by any concentration of capsaicin $\left(\mathrm{E}_{\max }\right)$ appeared to better discriminate chronic cough patients from healthy controls than 
conventional $\mathrm{C}_{2}$ and $\mathrm{C}_{5}$ endpoints. The study also suggested that a failure of descending inhibitory pathways might be a discriminating feature between patients with chronic cough and healthy controls [50]. This notion was supported in a recent study comparing the ability to voluntarily suppress cough in response to capsaicin inhalation; patients with chronic refractory cough were significantly less capable of suppressing cough than healthy controls [51].

Clinical value of cough challenge test is still uncertain. However, using different endpoints (such as $\mathrm{E}_{\max }[50]$ ) or a modified study protocol (such as cough suppression test [51]), it may contribute to discover the mechanisms underlying chronic cough. Capsaicin cough responses have been recently used as a proxy for neuronal sensitization in characterizing asthmatic patients $[52,53]$. In addition, by applying different tussigens, it may help confirm the mechanisms of novel antitussives [54,55], or explore the heterogeneity of cough hypersensitivity across individuals [56].

Brain functional magnetic resonance imaging studies may help identify the central neuronal processes responsible for chronic cough. In studies by Ando et al. [57], using low level concentrations of inhaled capsaicin, just sufficient to induce the "urge to cough," patients with chronic cough exhibited lower levels of activation in cortical regions implicated in cough inhibition (dorsomedial prefrontal and anterior mid-cingulate cortices) than healthy subjects.

\section{INSIGHTS FROM RECENT CLINICAL TRIALS WITH NOVEL PHARMACOLOGICAL AND NON-PHARMACOLOGICAL TREATMENTS FOR CHRONIC COUGH}

Successful outcomes in the treatment with opioids, gabapentin or pregabalin, support the notion that patients with chronic refractory cough may benefit from neuromodulatory treatments [29-31]. However, the relatively modest efficacy of these agents and the disabling side effects have hampered widespread use and prompted the search for more suitable cough treatments.

Since capsaicin, the active ingredient of chili pepper, is a well-known tussigen triggering the TRPV1 pathway, pharmacological inhibition of the TRPV1 path- way has gained scientific interest. However, clinical trials with two potent TRPV1 antagonists (SB-705498 and XEN-Do501) failed to reduce cough frequency or improve cough-specific QoL, while they significantly inhibited cough responses to capsaicin [55,58]. TRPA1 is a receptor sensing cold temperature $\left(<17^{\circ} \mathrm{C}\right)$ and a wide range of irritants including acrolein, allyl-isothiocyanate, or cinnamaldehyde which are abundant in air pollutants and cigarette smoke [59]. In humans, cold air is one of the most common triggers for coughing and TRPA1 stimulation was shown to mediate cough [6o]. However, the only TRPA1 antagonist to date having undergone early phase clinical development failed in a placebo-controlled trial of patients with chronic refractory cough [61]. This series of disappointments with specific TRP antagonists have galvanized the efforts to identify alternatives targeting other sensory neuronal receptors as potential antitussives [35].

ATP is a major damage-associated molecule released during cellular injury and which activates purinergic receptors. There are different subtypes in $\mathrm{P} 2 \mathrm{X}$ receptors according to their tissue or cellular distribution; $\mathrm{P}_{2} \mathrm{X}_{3}$ receptor is located primarily on peripheral neurons, thus making it a promising therapeutic target in neuropathic conditions [62]. Remarkably, in a proof-of-concept study of patients with chronic refractory cough, a $\mathrm{P}_{2} \mathrm{X}_{3}$ antagonist, $\mathrm{AF}-219$ (now called gefapixant), showed dramatic effects on objective cough frequency, cough severity, and cough-specific $\mathrm{QoL}[32]$, suggesting that $\mathrm{P}_{2} \mathrm{X}_{3}$ receptor is an integral part of the cough hypersensitivity pathway. Meanwhile, almost all patients developed taste disturbance during the treatment [32], which is now attributed to be the inhibition of $\mathrm{P}_{2} \mathrm{X}_{2} / 3$ channels by a high dose of gefapixant (60o mg twice a day). Thus, in two subsequent dose-ranging studies, different dosages of gefapixant were tested to optimize the efficacy and tolerability, which found that gefapixant at a lower dosage (30 or $50 \mathrm{mg}$ twice a day) may be appropriate for subsequent trials [63].

The success of $\mathrm{P}_{2} \mathrm{X}_{3}$ antagonists has led to the question of whether $\mathrm{P}_{2} \mathrm{X}_{3}$ is a single key molecule that regulates cough reflex hypersensitivity in chronic cough. However, inhalation of ATP did not cause a dramatic shift in cough sensitivity [49], suggesting that it may be merely a link in the chain rather than the driving engine of cough hypersensitivity [35]. Bonvini et al. [64] hypoth- 
esized a possible upstream regulator of ATP- $\mathrm{P}_{2} \mathrm{X}_{3}$ pathways and suggested a potential role of $\mathrm{TRPV}_{4}$ in regulating ATP- $\mathrm{P}_{2} \mathrm{X}_{3}$ in airway sensory neurons. However, a double-blind placebo-controlled clinical trial with a TRPV4 antagonist, GSK2798745, in patients with chronic cough showed negative results (ClinicalTrials.gov Identifier: NCT03372603). Thus, clinical relevance of TRPV4 remains to be further elucidated.

In a recent randomized placebo-controlled trial with gefapixant, inhalational cough challenge tests were sequentially performed with different tussigens such as ATP, capsaicin, citric acid, and distilled water [54]. Notably, gefapixant showed no effect on capsaicin and citric acid-induced coughs, while it significantly reduced cough sensitivity to ATP and distilled water. These findings suggest at least two distinct pathways in cough sensitivity; one mediated by purinergic pathways (responding to ATP and distilled water) with others independent of purinergic signals.

Larger clinical trials with gefapixant as well as other $\mathrm{P}_{2} \mathrm{X}_{3}$ selective antagonists (BAY1817080, BLU-5937, and $\mathrm{S}-600918)$ will finally confirm clinical roles of $\mathrm{P}_{2} \mathrm{X}_{3}$ antagonists in the management pathways of chronic cough. However, $\mathrm{P}_{2} \mathrm{X}_{3}$ may not be the sole pathway responsible for refractory cough, because gefapixant was not effective in some patients [32]. Also, it had no significant antitussive effects in patients with idiopathic pulmonary fibrosis (IPF)-associated cough [65]. In contrast, inhaled sodium cromoglycate, a mast cell stabilizer, was ineffective in controlling chronic refractory cough but improved IPF-associated cough [66]. Meanwhile, orvepitant, a neurokinin-1-receptor (NK1R) antagonist, showed benefits with improving subjective cough outcomes in patients with refractory cough [67], suggesting another therapeutic target in chronic cough. These altogether lead us to consider the heterogeneity in the mechanisms of chronic cough.

Heterogeneity in cough sensitivity was also shown in a recent study using cough challenge tests; patients with chronic obstructive pulmonary disease (COPD) showed enhanced cough sensitivity to capsaicin but a reduced response to prostaglandin $\mathrm{E} 2$ ( $\mathrm{PGE} 2$ ) compared to healthy controls, while patients with chronic cough had heightened cough response to capsaicin, citric acid, and PGE2 [44]. These findings collectively indicate that there are likely heterogeneous processes under- lying cough hypersensitivity across different patients and clinical conditions, and that that deciphering the heterogeneity would be key in developing the precise tools to control refractory cough. It is anticipated that the NEUROCOUGH Clinical Research Consortium, a multidisciplinary pan-European initiative endorsed by ERS [68], will provide the opportunity for precise phenotyping and molecular endotyping of chronic cough patients across a range of respiratory diseases, and thus, help generate further insights into the disease pathophysiology.

Meanwhile, non-pharmacological cough control therapy, or speech language and pathology therapy, is now considered a promising option for patients with chronic refractory cough, as demonstrated by randomised controlled trials $[69,70]$. The protocol is tailored for individual patient's traits, but briefly, its key components include education, cough control techniques, vocal hygiene and hydration, and psychoeducational counselling. Notably, it has essentially no side effects and may have sustained therapeutic benefits (up to 3 months' observation in a recent study [70]), when undertaken by professionals. With these strengths, in the coming years, its indication may extend to other chronic cough phenotypes than refractory cough; however, its efficacy and safety still needs to be proven in different cough phenotypes. Also, importantly, the service should be provided by experienced professionals. At present, the pool of individuals qualified for speech language and pathology therapy is lacking in many countries including Korea.

\section{NEW CONCEPTS TO CONSIDER IN THE EVALUATION AND MANAGEMENT OF CHRONIC COUGH}

While it is important to note that key principles of the anatomic diagnostic protocol remain valid, new approaches to the evaluation and management of cough are needed. To date, the key focus in controlling cough has centered on treating conditions such as asthma, rhinitis, or gastroesophageal reflux disease (GERD). However, placebo-controlled studies indicate that true therapeutic benefits gained from treating these conditions may be much less than the findings suggested from ob- 


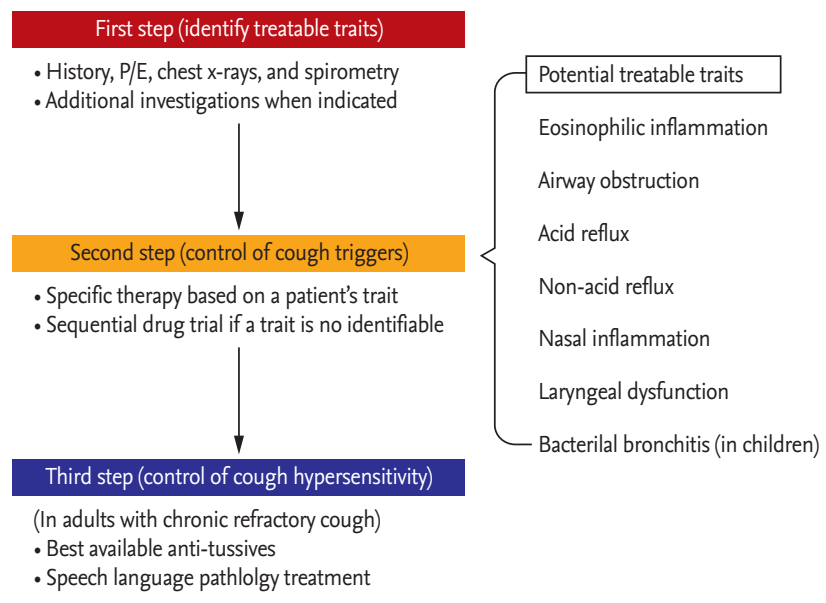

Figure 2. Clinical approach to chronic cough with a concept of cough hypersensitivity syndrome. The new paradigm highlights the importance of clinical thinking from the viewpoint of cough [8]; however, key principles of anatomic diagnostic protocols continue to be valid. The first step is to exclude any ongoing pathology such as malignancy, infection, foreign body inhalation or the use of an angiotensin converting enzyme inhibitor. Further investigations for asthma, eosinophilic bronchitis, reflux and esophageal dysmotility, and rhinosinusitis should be considered depending on the clinical history. Second step is to control any ongoing pathology (or treatable trait), such as eosinophilic inflammation or reflux, before considering cough control therapy. If a specific trait is not identifiable, it is suggested to undertake sequential therapeutic trials of each agent in turn. In adult patients who are refractory to the treatments, antitussives or speech language pathology treatment are considered. $\mathrm{P} / \mathrm{E}$, physical examination.

servational studies [71,72]. Cough is frequently self-limiting and prone to placebo effects [73], which may underlie the large discrepancy between placebo-controlled and uncontrolled (observational) studies.

An alternative to empiric trials of medicines, typically prescribed in a sequential manner is to take an approach based on identifying potential treatable traits [8], of which are worthy of consideration (Fig. 2).

Eosinophilic airway inflammation is a common feature of cough variant asthma and a defining characteristic of and eosinophilic bronchitis, which together may comprise up to $50 \%$ of chronic cough patients [74]. There is a controversy over direct causal effects of eosinophilic inflammation on cough, as anti-interleukin-5 monoclonal antibody, mepolizumab, did not affect cough while systemic corticosteroids did in patients with severe eosinophilic asthma [75]. However, it is much less arguable that eosinophilic airway inflammation is a treatable trait in chronic cough, because it is measurable in induced sputum and may predict corticosteroid responsiveness. Thus, the assessment and management of eosinophilic airway inflammation is recommended during the early stages of diagnostic work-up for chronic cough at specialist clinics $[6,9,20,75]$. However, there are practical issues in measuring eosinophilic airway inflammation, as induced sputum analysis is technically demanding and therefore restricted to specialist centers. Consequently, there is interest in developing practical alternatives to induced sputum tests, such as fractional exhaled nitric oxide (FeNO) measurement [76,77]. In a meta-analysis of observational studies, FeNO showed a promising utility in predicting the diagnosis of cough variant asthma, with specificity of 0.85 (95\% confidence interval [CI], 0.81 to 0.88 ) and sensitivity of 0.72 (95\% CI, 0.61 to 0.81 ) [76]. However, it showed a relatively poor predictability for sputum eosinophilia in patients with asthma or chronic cough $[76,77]$. In placebo-controlled trials, high FeNO levels were significantly associated with good corticosteroid responsiveness in patients with respiratory symptoms including cough [78,79]; however, it is unclear whether these findings could be directly translated into patients with isolated chronic cough. So far, there is no quality evidence to make strong recommendations for the routine use of FeNO in patients with chronic cough [8]. It is our view that in time, FeNO will emerge as an important treatable trait to consider in patients referred with chronic cough.

Obstructive lung diseases, such as asthma or COPD, are frequently associated with cough, and bronchodilators are the main therapeutic options (often in combination with inhaled corticosteroid [ICS]). Methacholine-induced bronchoconstriction may increase capsaicin cough responses in asthmatics [8o]. However, the roles of bronchodilator therapy in managing chronic cough remain largely unclear. To our knowledge, most clinical trials of bronchodilator therapy in patients with asthma or COPD have not utilized validated cough measurement tools and rarely report cough endpoints. A small number of trials have suggested of the efficacy of treating airway obstruction in patients complaining chronic cough. In a placebo-controlled trial of 15 patients with chronic cough, treatment with an inhaled bronchodilator was effective in reducing cough severity 
score in a subset of asthmatic patients with cough [81]. In patients with chronic productive cough and COPD, a combination of ICS and salmeterol showed some improvements in cough scores compared to placebo, but the inter-group difference in cough score was relatively small and difficult to translate clinically [82]. Importantly, further studies are warranted to confirm whether airway obstruction is a major treatable trait in chronic cough.

GERD has been a controversial entity in terms of clinical relevance to cough. Systematic reviews of placebo-controlled trials demonstrated that acid suppressive therapy such as proton pump inhibitor (PPI) showed almost no benefits over placebo in cough patients without acid reflux (therapeutic gain; range, $0.0 \%$ to $8.6 \%$ ), and only modest therapeutic gains in patients with pathologic acid reflux (range, 12.5\% to 35.8\%) [71]. These findings support the notion that a routine anti-acid therapy is not indicated but should be reserved for a subgroup with symptoms of acid reflux and/or evidence of pathological acid reflux on diagnostic testing; this view has been reflected in recent guideline recommendations $[8,9,83]$. Indeed, the relationships between cough and reflux are likely to be complex, as cough can frequently induce reflux and reflux can also provoke cough (thus can be self-perpetuating) [84]. PPI is generally safe, but there are potential concerns about adverse drug reactions problematic in the elderly, such as iron deficiency, vitamin B12 deficiency, hypomagnesemia, osteoporosis-related bone fracture, dementia, or pneumonia [14]. Although direct reports are sparse, there is a concern that PPI is being frequently prescribed without a clear rationale in subjects with chronic cough [85].

Meanwhile, recent studies suggest potential implications of non-acid reflux in chronic cough $[84,86,87]$; however, there are no controlled trials with prokinetics or reflux inhibitors in patients with chronic cough. Thus, further studies are warranted to confirm if non-acid reflux is clinically relevant to chronic cough.

Rhinitis or rhinosinusitis is one of the conditions that has been most frequently associated with chronic cough, particularly in Asia $[13,88]$. In a previous survey of physicians in Korea, upper airway cough syndrome was perceived as the most common cause of chronic cough and paranasal sinus radiography was one of the most frequently considered diagnostic tests [89]. However, mechanistically, it does not directly trigger cough via vagus nerves, while nasal inflammation may sensitize the cough reflex through activation of trigeminal nerves [90]. In an observational study of 89 subjects with purulent post-nasal drip, approximately $9 \%$ of them complained of cough, in the absence of lung diseases [91]. In a recent study, patients with chronic post-nasal drip showed significantly decreased nasopharyngeal sensitivity to air puff instillation than healthy controls [92]. In addition, to our knowledge, there is no placebo-controlled trial to confirm the benefits of second-generation $\mathrm{H1}$-antihistamines or intranasal corticosteroids in patients with chronic cough and nasal symptoms, using validated outcomes for cough. Thus, further works are warranted to determine whether nasal inflammation is a treatable trait in chronic cough.

Laryngeal dysfunction is likely to be common in patients with chronic refractory cough [93], which is not surprising given the protective role of the larynx for the lower airways. However, precise roles of laryngeal dysfunction have not been confirmed in chronic cough [94]. Two observational studies suggested the potential benefit of gabapentin therapy for cough patients with abnormal motion of the larynx $[95,96]$. In clinical experience, it is suggested that speech language and pathology therapy including breathing technique education may be beneficial in chronic cough patients with comorbid laryngeal dysfunction [97]. Controlled trials with the measurement of laryngeal behavior will help understand and confirm the clinical relevance of laryngeal dysfunction in chronic cough.

Chronic cough in children is beyond the scope of the present review. However, certain etiologies of chronic cough in children are considered distinct from those in adults [98]. Common causes in children may differ between regions and clinical settings, but commonly include protracted bacterial bronchitis (PBB), tracheomalacia, bronchiectasis, asthma and post-infectious cough [8]; these findings are attributed to structural or immunologic maturation processes affecting the cough reflex pathways are occurring in childhood. Amongst various conditions, $\mathrm{PBB}$ is considered to be a distinct common entity in infants and young children with chronic wet cough [99]. The prevalence of PBB is not reported in Korean children, but the data from Australia, Turkey, and China indicate that it is one of the most common 
causes of chronic wet cough in young children [99-101]. In the recent ERS Task Force report, a consensus definition has been formulated as the following: (1) presence of chronic (> 4 weeks' duration) wet or productive cough; (2) absence of symptoms or signs (i.e., specific cough pointers) suggestive of other causes of wet or productive cough; and (3) cough resolved following a 2 to 4 -week course of an appropriate oral antibiotic [99]. Recent international and domestic guidelines commonly recommend a trial of antibiotics therapy in young children with chronic wet cough, normal chest X-rays, normal spirometry, and no warning signs $[8,9,102]$. Meanwhile, it is unknown whether a clinical entity like PBB exists in adults. However, a recent observational study in United Kingdom described that a cohort of adult patients with chronic productive cough and sputum neutrophilia who had been unexplained by existing disease labels but showed a significant response to a 3-month azithromycin treatment [103].

Cough hypersensitivity is becoming more measurable and controllable $[32,47,49,63,67,69,70]$, and thus it may be considered as a treatable trait in chronic cough. However, this concept is still reserved for adults with chronic refractory cough (Fig. 2). It is usually considered that chronic cough without identifiable organic or anatomical causes is uncommon in children [98].

In summary, there are very few practical biomarkers that have been found to be useful in identifying a treatable trait or predicting a specific treatment response. As previously discussed, while there are no proven alternatives to induced sputum tests in defining eosinophilic airway inflammation or predicting ICS response, FeNO is likely to have an increasing prominent role. The clinical utility of methacholine bronchial challenge tests is unclear in predicting ICS treatment response among patients with isolated chronic cough, as non-asthmatic eosinophilic bronchitis is relatively commonly associated with chronic cough $[20,88,104]$. Heartburn symptoms are considered a biomarker to guide acid suppressive therapy $[8,9,83]$; however, the value of this symptom biomarker may be limited [105]. There are no biomarkers to guide H1-antihistamine therapy in chronic cough patients. Therefore, current clinical approaches are mostly based on therapeutic trials and further work is necessary to develop a precise clinical strategy for chronic cough [8].

\section{CONCLUSIONS}

In the last few decades, there have been important advances in the clinical and scientific understanding of cough. Importantly, the concept of CHS has been introduced, and it is gaining widespread endorsement within the allergy and respiratory community. There are now increasing numbers of successful clinical trials with novel antitussives and speech language pathology therapy, which is a very welcome news to patients with refractory cough and the clinicians. Central to this has been an appreciation of the neurobiology of cough; however, significant gaps in knowledge exist and new challenges are emerging on a regular basis particularly regarding clinical translation of exciting preclinical entities. In addition, there is a pressing need to educate clinicians and health care providers as to the importance of chronic cough as a common clinical condition that hampers the lives of patients. There is currently a real sense of optimism in this field and, in order to realize the potential of the remarkable progress in clinical evaluation and drug discovery, there is a need for clinicians, scientists, the industry, and patient organisations to work collectively. Efforts to achieve this goal are well advanced.

\section{Conflict of interest}

Woo-Jung Song reports grants from Astra Zeneca and MSD outside the submitted work. Jin An has nothing to disclose. Lorcan McGarvey reports grants and consultancy/speaker fees from Merck \& Co., Inc., Bayer, Chiesi and Bellus Health and consultancy/speaker fees from GlaxoSmithKline, and Boehringer Ingelheim.

\section{REFERENCES}

1. Pitts T. Airway protective mechanisms. Lung 2014;192:27-31.

2. Canning BJ, Chang AB, Bolser DC, et al. Anatomy and neurophysiology of cough: CHEST guideline and expert panel report. Chest 2014;146:1633-1648.

3. Chung KF, McGarvey L, Mazzone SB. Chronic cough as a neuropathic disorder. Lancet Respir Med 2013;1:414-422.

4. Ebell MH, Lundgren J, Youngpairoj S. How long does a cough last?: comparing patients' expectations with data from a systematic review of the literature. Ann Fam Med 2013;11:5-13. 
5. Hay AD, Little P, Harnden A, et al. Effect of oral prednisolone on symptom duration and severity in nonasthmatic adults with acute lower respiratory tract infection: a randomized clinical trial. JAMA 2017;318:721-730.

6. Irwin RS, French CL, Chang AB, Altman KW; CHEST Expert Cough Panel. Classification of cough as a symptom in adults and management algorithms: CHEST guideline and expert panel report. Chest 2018;153:196-209.

7. Morice AH, McGarvey L, Pavord I; British Thoracic Society Cough Guideline Group. Recommendations for the management of cough in adults. Thorax 2006;61 Suppl 1(Suppl 1):iı-i24.

8. Morice AH, Millqvist E, Bieksiene K, et al. ERS guidelines on the diagnosis and treatment of chronic cough in adults and children. Eur Respir J 2020;55:1901136.

9. Song DJ, Song WJ, Kwon JW, et al. KAAACI evidence-based clinical practice guidelines for chronic cough in adults and children in Korea. Allergy Asthma Immunol Res 2018;10:591-613.

10. Lai K, Shen H, Zhou X, et al. Clinical practice guidelines for diagnosis and management of cough: Chinese Thoracic Society (CTS) Asthma Consortium. J Thorac Dis 2018;10:6314-6351.

11. Song WJ, Chang YS, Faruqi S, et al. The global epidemiology of chronic cough in adults: a systematic review and meta-analysis. Eur Respir J 2015;45:1479-1481.

12. Kang MG, Song WJ, Kim HJ, et al. Point prevalence and epidemiological characteristics of chronic cough in the general adult population: the Korean National Health and Nutrition Examination Survey 2010-2012. Medicine (Baltimore) 2017;96:e6486.

13. Song WJ, Faruqi S, Klaewsongkram J, Lee SE, Chang YS. Chronic cough: an Asian perspective. Part 1: epidemiology. Asia Pac Allergy 2015;5:136-144.

14. Song WJ, Won HK, An J, et al. Chronic cough in the elderly. Pulm Pharmacol Ther 2019;56:63-68.

15. French CL, Irwin RS, Curley FJ, Krikorian CJ. Impact of chronic cough on quality of life. Arch Intern Med 1998;158:1657-1661.

16. Birring SS, Prudon B, Carr AJ, Singh SJ, Morgan MD, Pavord ID. Development of a symptom specific health status measure for patients with chronic cough: Leicester Cough Questionnaire (LCQ). Thorax 2003;58:339-343.

17. Hulme K, Dogan S, Parker SM, Deary V. 'Chronic cough, cause unknown': a qualitative study of patient perspectives of chronic refractory cough. J Health Psychol
2019;24:707-716.

18. Kang SY, Won HK, Lee SM, et al. Impact of cough and unmet needs in chronic cough: a survey of patients in Korea. Lung 2019;197:635-639.

19. Irwin RS, Corrao WM, Pratter MR. Chronic persistent cough in the adult: the spectrum and frequency of causes and successful outcome of specific therapy. Am Rev Respir Dis 1981;123(4 Pt 1):413-417.

20. Morice AH, Fontana GA, Sovijarvi AR, et al. The diagnosis and management of chronic cough. Eur Respir J 2004;24:481-492.

21. McGarvey L. The difficult-to-treat, therapy-resistant cough: why are current cough treatments not working and what can we do? Pulm Pharmacol Ther 2013;26:528531.

22. Morice AH. The cough hypersensitivity syndrome: a novel paradigm for understanding cough. Lung 2010;188 Suppl 1:S87-S9o.

23. Chung KF. Chronic 'cough hypersensitivity syndrome': a more precise label for chronic cough. Pulm Pharmacol Ther 2011;24:267-271.

24. Morice AH, Millqvist E, Belvisi MG, et al. Expert opinion on the cough hypersensitivity syndrome in respiratory medicine. Eur Respir J 2014;44:1132-1148.

25. Vertigan AE, Gibson PG. Chronic refractory cough as a sensory neuropathy: evidence from a reinterpretation of cough triggers. J Voice 2011;25:596-601.

26. Hilton E, Marsden P, Thurston A, Kennedy S, Decalmer $S$, Smith JA. Clinical features of the urge-to-cough in patients with chronic cough. Respir Med 2015;109:701-707.

27. Won HK, Kang SY, Kang Y, et al. Cough-related laryngeal sensations and triggers in adults with chronic cough: symptom profile and impact. Allergy Asthma Immunol Res 2019;11:622-631.

28. Song WJ, Chung KF. Exploring the clinical relevance of cough hypersensitivity syndrome. Expert Rev Respir Med 2020;14:275-284.

29. Morice AH, Menon MS, Mulrennan SA, et al. Opiate therapy in chronic cough. Am J Respir Crit Care Med 2007;175:312-315.

30. Ryan NM, Birring SS, Gibson PG. Gabapentin for refractory chronic cough: a randomised, double-blind, placebo-controlled trial. Lancet 2012;380:1583-1589.

31. Vertigan AE, Kapela SL, Ryan NM, Birring SS, McElduff P, Gibson PG. Pregabalin and speech pathology combination therapy for refractory chronic cough: a randomized 
controlled trial. Chest 2016;149:639-648.

32. Abdulqawi R, Dockry R, Holt K, et al. $\mathrm{P}_{2} \mathrm{X}_{3}$ receptor antagonist (AF-219) in refractory chronic cough: a randomised, double-blind, placebo-controlled phase 2 study. Lancet 2015;385:1198-1205.

33. Mazzone SB, Chung KF, McGarvey L. The heterogeneity of chronic cough: a case for endotypes of cough hypersensitivity. Lancet Respir Med 2018;6:636-646.

34. Birring SS, Spinou A. How best to measure cough clinically. Curr Opin Pharmacol 2015;22:37-40.

35. Song WJ, Morice AH. Cough hypersensitivity syndrome: a few more steps forward. Allergy Asthma Immunol Res 2017;9:394-402.

36. Atkinson SK, Sadofsky LR, Morice AH. How does rhinovirus cause the common cold cough? BMJ Open Respir Res 2016;3:eooo118.

37. O'Connell F, Thomas VE, Studham JM, Pride NB, Fuller RW. Capsaicin cough sensitivity increases during upper respiratory infection. Respir Med 1996;90:279-286.

38. Abdullah H, Heaney LG, Cosby SL, McGarvey LP. Rhinovirus upregulates transient receptor potential channels in a human neuronal cell line: implications for respiratory virus-induced cough reflex sensitivity. Thorax 2014;69:4654 .

39. Zaccone EJ, Lieu T, Muroi Y, et al. Parainfluenza 3-induced cough hypersensitivity in the Guinea Pig Airways. PLoS One 2016;11:e0155526.

40. Lieu TM, Myers AC, Meeker S, Undem BJ. TRPVı induction in airway vagal low-threshold mechanosensory neurons by allergen challenge and neurotrophic factors. Am J Physiol Lung Cell Mol Physiol 2012;302:L941-L948.

41. Lee LY, Gu Q, Lin AH, Khosravi M, Gleich G. Airway hypersensitivity induced by eosinophil granule-derived cationic proteins. Pulm Pharmacol Ther 2019;57:101804.

42. Drake MG, Scott GD, Blum ED, et al. Eosinophils increase airway sensory nerve density in mice and in human asthma. Sci Transl Med 2018;10:eaar8477.

43. Satia I, Watson R, Scime T, et al. Allergen challenge increases capsaicin-evoked cough responses in patients with allergic asthma. J Allergy Clin Immunol 2019;144:788-795.

44. Belvisi MG, Birrell MA, Khalid S, et al. Neurophenotypes in airway diseases: insights from translational cough studies. Am J Respir Crit Care Med 2016;193:1364-1372.

45. Lv H, Yue J, Chen Z, et al. Effect of transient receptor potential vanilloid-1 on cough hypersensitivity induced by particulate matter 2.5. Life Sci 2016;151:157-166.
46. Jo EJ, Song WJ. Environmental triggers for chronic cough. Asia Pac Allergy 2019;9:e16.

47. Morice AH, Fontana GA, Belvisi MG, et al. ERS guidelines on the assessment of cough. Eur Respir J 2007;29:12561276.

48. McGarvey LP, Heaney LG, Lawson JT, et al. Evaluation and outcome of patients with chronic non-productive cough using a comprehensive diagnostic protocol. Tho$\operatorname{rax} 1998 ; 53: 738-743$.

49. Fowles HE, Rowland T, Wright C, Morice A. Tussive challenge with ATP and AMP: does it reveal cough hypersensitivity? Eur Respir J 2017;49:1601452.

50. Hilton EC, Baverel PG, Woodcock A, van der Graaf PH, Smith JA. Pharmacodynamic modeling of cough responses to capsaicin inhalation calls into question the utility of the $\mathrm{C}_{5}$ end point. J Allergy Clin Immunol 2013;132:847-855.

51. Cho PS, Fletcher HV, Turner RD, Jolley CJ, Birring SS. Impaired cough suppression in chronic refractory cough. Eur Respir J 2019;53:1802203.

52. Satia I, Tsamandouras N, Holt K, et al. Capsaicin-evoked cough responses in asthmatic patients: evidence for airway neuronal dysfunction. J Allergy Clin Immunol 2017;139:771-779.

53. Kanemitsu Y, Fukumitsu K, Kurokawa R, et al. Increased capsaicin sensitivity in severe asthmatics associated with worse clinical outcome. Am J Respir Crit Care Med 2020;201:1068-1077.

54. Morice AH, Kitt MM, Ford AP, et al. The effect of gefapixant, a $\mathrm{P}_{2} \mathrm{X}_{3}$ antagonist, on cough reflex sensitivity: a randomised placebo-controlled study. Eur Respir J 2019;54:1900439.

55. Belvisi MG, Birrell MA, Wortley MA, et al. XEN-Do501, a novel transient receptor potential vanilloid 1 antagonist, does not reduce cough in patients with refractory cough. Am J Respir Crit Care Med 2017;196:1255-1263.

56. Long L, Yao H, Tian J, et al. Heterogeneity of cough hypersensitivity mediated by TRPV 1 and TRPA1 in patients with chronic refractory cough. Respir Res 2019;20:112.

57. Ando A, Smallwood D, McMahon M, Irving L, Mazzone SB, Farrell MJ. Neural correlates of cough hypersensitivity in humans: evidence for central sensitisation and dysfunctional inhibitory control. Thorax 2016;71:323-329.

58. Khalid S, Murdoch R, Newlands A, et al. Transient receptor potential vanilloid 1 (TRPVI) antagonism in patients with refractory chronic cough: a double-blind randomized controlled trial. J Allergy Clin Immunol 2014;134:56- 
62.

59. Geppetti P, Patacchini R, Nassini R, Materazzi S. Cough: the emerging role of the TRPA1 channel. Lung 2010;188 Suppl 1:S63-S68.

6o. Birrell MA, Belvisi MG, Grace M, et al. TRPAı agonists evoke coughing in guinea pig and human volunteers. Am J Respir Crit Care Med 2009;180:1042-1047.

61. Morice AH. TRPA1 receptors in chronic cough. Pulm Pharmacol Ther 2017;47:42-44.

62. Burnstock G, Brouns I, Adriaensen D, Timmermans JP. Purinergic signaling in the airways. Pharmacol Rev 2012;64:834-868.

63. Smith JA, Kitt MM, Butera P, et al. Gefapixant in two randomised dose-escalation studies in chronic cough. Eur Respir J 2020:1901615.

64. Bonvini SJ, Birrell MA, Grace MS, et al. Transient receptor potential cation channel, subfamily V, member 4 and airway sensory afferent activation: role of adenosine triphosphate. J Allergy Clin Immunol 2016;138:249-261.

65. Martinez FJ, Afzal A, Kitt MM, et al. The treatment of chronic cough in idiopathic pulmonary fibrosis patients with gefapixant, a P2x3 receptor antagonist. Am J Respir Crit Care Med 2019;199:A2638.

66. Birring SS, Wijsenbeek MS, Agrawal S, et al. A novel formulation of inhaled sodium cromoglicate (PA101) in idiopathic pulmonary fibrosis and chronic cough: a randomised, double-blind, proof-of-concept, phase 2 trial. Lancet Respir Med 2017;5:806-815.

67. Smith J, Allman D, Badri H, et al. The neurokinin-1 receptor antagonist orvepitant is a novel antitussive therapy for chronic refractory cough: results from a phase 2 pilot study (VOLCANO-1). Chest 2020;157:111-118.

68. McGarvey L, Dupont L, Birring SS, et al. New understanding in the treatment of cough (NEUROCOUGH) ERS Clinical Research Collaboration: improving care and treatment for patients with cough. Eur Respir J 2019;53:1900787.

69. Vertigan AE, Theodoros DG, Gibson PG, Winkworth AL. Efficacy of speech pathology management for chronic cough: a randomised placebo controlled trial of treatment efficacy. Thorax 2006;61:1065-1069.

70. Chamberlain Mitchell SA, Garrod R, Clark L, et al. Physiotherapy, and speech and language therapy intervention for patients with refractory chronic cough: a multicentre randomised control trial. Thorax 2017;72:129-136.

71. Kahrilas PJ, Howden CW, Hughes N, Molloy-Bland M.
Response of chronic cough to acid-suppressive therapy in patients with gastroesophageal reflux disease. Chest 2013;143:605-612.

72. Lee SE, Lee JH, Kim HJ, et al. Inhaled corticosteroids and placebo treatment effects in adult patients with cough: a systematic review and meta-analysis. Allergy Asthma Immunol Res 2019;11:856-870.

73. Eccles R. The powerful placebo effect in cough: relevance to treatment and clinical trials. Lung 2020;198:13-21.

74. Chung KF, Pavord ID. Prevalence, pathogenesis, and causes of chronic cough. Lancet 2008;371:1364-1374.

75. Diver S, Russell RJ, Brightling CE. Cough and eosinophilia. J Allergy Clin Immunol Pract 2019;7:1740-1747.

76. Song WJ, Kim HJ, Shim JS, et al. Diagnostic accuracy of fractional exhaled nitric oxide measurement in predicting cough-variant asthma and eosinophilic bronchitis in adults with chronic cough: a systematic review and metaanalysis. J Allergy Clin Immunol 2017;140:701-709.

77. Korevaar DA, Westerhof GA, Wang J, et al. Diagnostic accuracy of minimally invasive markers for detection of airway eosinophilia in asthma: a systematic review and meta-analysis. Lancet Respir Med 2015;3:290-300.

78. Smith AD, Cowan JO, Brassett KP, et al. Exhaled nitric oxide: a predictor of steroid response. Am J Respir Crit Care Med 2005;172:453-459.

79. Price DB, Buhl R, Chan A, et al. Fractional exhaled nitric oxide as a predictor of response to inhaled corticosteroids in patients with non-specific respiratory symptoms and insignificant bronchodilator reversibility: a randomised controlled trial. Lancet Respir Med 2018;6:29-39.

8o. Satia I, Badri H, Woodhead M, O'Byrne PM, Fowler SJ, Smith JA. The interaction between bronchoconstriction and cough in asthma. Thorax 2017;72:1144-1146.

81. Irwin RS, French CT, Smyrnios NA, Curley FJ. Interpretation of positive results of a methacholine inhalation challenge and 1 week of inhaled bronchodilator use in diagnosing and treating cough-variant asthma. Arch Intern Med 1997;157:1981-1987.

82. Calverley P, Pauwels R, Vestbo J, et al. Combined salmeterol and fluticasone in the treatment of chronic obstructive pulmonary disease: a randomised controlled trial. Lancet 2003;361:449-456.

83. Kahrilas PJ, Altman KW, Chang AB, et al. Chronic cough due to gastroesophageal reflux in adults: CHEST guideline and expert panel report. Chest 2016;150:1341-1360.

84. Smith JA, Decalmer S, Kelsall A, et al. Acoustic cough-re- 
flux associations in chronic cough: potential triggers and mechanisms. Gastroenterology 2010;139:754-762.

85. Rane PP, Guha S, Chatterjee S, Aparasu RR. Prevalence and predictors of non-evidence based proton pump inhibitor use among elderly nursing home residents in the US. Res Social Adm Pharm 2017;13:358-363.

86. Herregods TV, Pauwels A, Jafari J, et al. Determinants of reflux-induced chronic cough. Gut 2017;66:2057-2062.

87. Burke JM, Jackson W, Morice AH. The role of high resolution oesophageal manometry in occult respiratory symptoms. Respir Med 2018;138:47-49.

88. Kang SY, Kim GW, Song WJ, Chang YS, Cho SH. Chronic cough in Korean adults: a literature review on common comorbidity. Asia Pac Allergy 2016;6:198-206.

89. Kim SH, Kim SH, Song WJ, et al. Allergists' perceptions and practices on the management of chronic cough in Korea: a questionnaire survey. Korean J Asthma Allergy Clin Immunol 2012;32:239-253.

90. Plevkova J, Song WJ. Chronic cough in subjects with upper airway diseases: analysis of mechanisms and clinical applications. Asia Pac Allergy 2013;3:127-135.

91. O’Hara J, Jones NS. "Post-nasal drip syndrome": most patients with purulent nasal secretions do not complain of chronic cough. Rhinology 2006;44:270-273.

92. Bucher S, Schmid-Grendelmeier P, Soyka MB. Altered viscosity of nasal secretions in postnasal drip. Chest 2019;156:659-666.

93. Vertigan AE, Kapela SM, Kearney EK, Gibson PG. Laryngeal dysfunction in cough hypersensitivity syndrome: a cross-sectional observational study. J Allergy Clin Immunol Pract 2018;6:2087-2095.

94. Song WJ. Laryngeal dysfunction in chronic cough: a sign for specific cough endotype? J Allergy Clin Immunol Pract 2018;6:2096-2097.

95. Lee B, Woo P. Chronic cough as a sign of laryngeal sensory neuropathy: diagnosis and treatment. Ann Otol Rhinol
Laryngol 2005;114:253-257.

96. Giliberto JP, Dibildox D, Merati A. Unilateral laryngoscopic findings associated with response to gabapentin in patients with chronic cough. JAMA Otolaryngol Head Neck Surg 2017;143:1081-1085.

97. Vertigan AE, Haines J, Slovarp L. An update on speech pathology management of chronic refractory cough. J Allergy Clin Immunol Pract 2019;7:1756-1761.

98. Chang AB, Oppenheimer JJ, Weinberger M, et al. Etiologies of chronic cough in pediatric cohorts: CHEST guideline and expert panel report. Chest 2017;152:607-617.

99. Kantar A, Chang AB, Shields MD, et al. ERS statement on protracted bacterial bronchitis in children. Eur Respir J 2017;50:1602139.

100. Wang Y, Hao C, Chi F, et al. Clinical characteristics of protracted bacterial bronchitis in Chinese infants. Sci Rep 2015;5:13731.

101. Laird P, Totterdell J, Walker R, Chang AB, Schultz A. Prevalence of chronic wet cough and protracted bacterial bronchitis in Aboriginal children. ERJ Open Res 2019;5:00248-2019.

102. Chang AB, Oppenheimer JJ, Weinberger MM, et al. Management of children with chronic wet cough and protracted bacterial bronchitis: CHEST guideline and expert panel report. Chest 2017;151:884-890.

103. Martin MJ, Lee H, Clayton C, et al. Idiopathic chronic productive cough and response to open-label macrolide therapy: an observational study. Respirology 2019;24:558565.

104. Gibson PG, Dolovich J, Denburg J, Ramsdale EH, Hargreave FE. Chronic cough: eosinophilic bronchitis without asthma. Lancet 1989;1:1346-1348.

105. Badri H, Satia I, Woodcock A, Smith JA. The usefulness of heartburn as a marker of the success of acid suppression therapy in chronic cough. Thorax 2014;69(Suppl 2):A82-A83. 